\title{
Reflexões sobre democracia, SUS e saúde bucal como direito.
}

\section{Reflections on democracy, SUS and oral health as a right.}

\section{Reflexiones sobre la democracia, el SUS y la salud oral como un derecho.}

Swedenberger do Nascimento Barbosa ${ }^{1}$

RESUMO: O objetivo do trabalho é relacionar a conquista democrática do Direito à saúde e sua formalização, a partir da Constituição Federal do Brasil,de1988, destacando a contribuição das Conferências Nacionais de Saúde para alcançar tal objetivo. No caso específico, como as Conferências Nacionais de Saúde Bucal, contribuíram para alcançar a atual Política Nacional de Saúde Bucal (PNSB) e o desafio de manter e ampliar este direito de cidadania, de forma ética e responsável pelos próximos anos. São apresentados conceitos de democracia, cidadania e direitos como conquista, num percurso histórico em que as lutas democráticas lograram êxito em alcançar políticas sociais de caráter público e universal, como o SUS., como um dever do Estado e um direito de todos. São citados estudos que permitem elevar preocupações quanto a continuidades das atuais políticas sociais de caráter universal e neste sentido, busca-se demonstrar que está em curso retrocessos na democracia brasileira, com um "modelo" proposto de Estado Mínimo que, se efetivado plenamente, não garantirá as políticas universais necessárias a atender os interesses da maioria da população brasileira. Por fim, busca-se estabelecer alguns pressupostos para que se possa manter os direitos e conquistas como avanços civilizatórios e éticos.

Palavras-chave: Democracia;Cidadania;Direitos; Sistema Único de Saúde;Saúde Bucal.

ABSTRACT: The objective of this paper is to relate the democratic conquest of the Right to Health and its formalization, based on the Federal Constitution of Brazil, of 1988, highlighting the contribution of the National Health Conferences to achieve this goal. In the specific case, such as the National Oral Health Conferences, contributed to achieve the current National Oral Health Policy (PNSB) and the challenge of maintaining and expanding this right of citizenship, ethically and responsibly for the next years. Concepts of democracy, citizenship and rights as conquest are 1 Doutor e Mestre em Ciências da Saúde, Especialista em Saúde Pública e Saúde Coletiva. Programa de Pós-Graduação em Ciências da Saúde.UNB Pesquisador Colaborador da Fiocruz.BSB

ISSN 1982-8829 Tempus, actas de saúde colet, Brasília, 13(3), 169-181, set, 2019. Epub Jul/2020 
presented in a historical course in which democratic struggles have succeeded in achieving public and universal social policies, such as SUS, as a duty of the state and a right of all. Studies are cited that raise concerns about the continuity of current social policies of universal character and in this sense, we seek to demonstrate that setbacks are underway in Brazilian democracy, with a proposed "model" of the Minimum State that, if fully implemented, does not will guarantee the universal policies necessary to meet the interests of the majority of the Brazilian population. Finally, we seek to establish some assumptions so that rights and achievements can be maintained as civilizing and ethical advances.

Key-worlds: Democracy; Rights; Citizenship;Unified Health System; Oral Health

RESUMEN: El objetivo de este documento es relacionar la conquista democrática del Derecho a la Salud y su formalización, basada en la Constitución Federal de Brasil, de 1988, destacando la contribución de las Conferencias Nacionales de Salud para lograr este objetivo. En el caso específico, como las Conferencias Nacionales de Salud Oral, contribuyó a lograr la Política Nacional de Salud Oral (PNSB) actual y el desafío de mantener y expandir este derecho de ciudadanía, de manera ética y responsable durante los próximos años. Los conceptos de democracia, ciudadanía y derechos como conquista se presentan en un curso histórico en el que las luchas democráticas han logrado lograr políticas sociales públicas y universales, como el SUS, como un deber del Estado $\mathrm{y}$ un derecho de todos. Se citan estudios que plantean preocupaciones sobre la continuidad de las políticas sociales actuales de carácter universal y, en este sentido, buscamos demostrar que existen retrocesos en la democracia brasileña, con un "modelo" propuesto del Estado Mínimo que, si se implementa completamente, no garantizará las políticas universales necesarias para satisfacer los intereses de la mayoría de la población brasileña. Finalmente, buscamos establecer algunos supuestos para que los derechos y logros puedan mantenerse como avances civilizadores y éticos. Contraseñas: Democracia; Ciudadanía; derechos; , Sistema Único de Salud; Salud bucal

\section{INTRODUÇÃO}

A Constituição Brasileira de 1988 foi um marco da democracia de massas no país pela inclusão de toda população no processo político e democrático ao consagrar o direito de voto do analfabeto, a universalização de direitos sociais, com especial atenção ao direito à saúde como direito de todos e dever do Estado, e pela novidade da incorporação de elementos participativos em seu texto, para além dos processos eleitorais e dos limites da democracia representativa. Enfim, um processo que marca, com conflitos e tensões, o protagonismo e a escolha ativa da sociedade brasileira por um projeto solidário e inclusivo de país.(1)

A mobilização ocorrida por ocasião da Assembleia Constituinte vem carregada de diversas iniciativas populares, com o apoio massivo de entidades da sociedade civil, de trabalhadores, categorias e movimentos diversos. A movimentação ocorrida para a $8^{\text {a }}$ Conferência Nacional de Saúdeem torno da Reforma Sanitária e da democracia,foi essencial para embasar o capítulo da 
Seguridade Social, em especial, nas diretrizes do Sistema Único de Saúde (SUS) e na formulação da Saúde como um direito de todos e dever do Estado.(1)

Garantiu-se um sistema de proteção social importante, com avanços nos pilares da Seguridade Social: saúde, previdência social e assistência social, como direitos fundamentais. No caso da saúde, a expressão"Saúde é democracia" decorre da ideia defendida pelo sanitarista Sergio Arouca em seu discurso de abertura na $8^{\text {a }}$ Conferência Nacional de Saúde ( $\left.8^{\text {a }} \mathrm{CNS}\right)$, realizada em 1986. Naquele momento, em pleno processo de redemocratização do Brasil, discutia-se um novo paradigma do conceito ampliado de saúde como direito, que se materializa, apesar de todas as resistências políticas e econômicas, na criação do Sistema Único de Saúde (SUS).(2)

A saúde bucal está, desde aqueles momentos, envolvida na construção social deste direito, a partir de um setor progressista de sua categoria, de estudantes, professores e alguns ativos militantes de entidades odontológicas e do serviço público.

Esses segmentos da Odontologia que já participavam dos fóruns da Reforma Sanitária,construíram e/ou estimularam a criação de espaços democráticos de discussão, como o MBRO(Movimento Brasileiro de Renovação Odontológica), os ECEOS(Encontros Científicos de Estudantes de Odontologia) eos ENATESPOS (Encontro Nacional de Administradores e Técnicos do Serviço Público Odontológico). Desde aqueles momentos, as discussões situavam-se na defesa da saúde bucal como direito de cidadania e de sua incorporação no âmbito das políticas públicas de saúde, ou seja, do SUS a ser construído.

\section{SAÚDE BUCAL COMO DIREITO}

\section{AS CONFERÊNCIAS NACIONAIS DE SAÚDE BUCAL}

A articulação em torno de setores da Odontologia e sua integração ao movimento da Reforma Sanitária, contribuiu para a viabilização da1 a Conferência Nacional de Saúde Bucal em 1986, já,

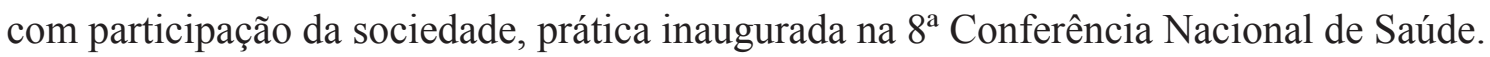

As duas conferências nacionais de saúde bucal realizadas (1986 e 1993) delinearam, com destaque, a Política Nacional de Saúde Bucal, implementada a partir de 2004. Neste mesmo ano, seria realizada a $3^{\text {a }}$ conferência Nacional de Saúde Bucal, aprovando a Política Nacional de Saúde Bucal e reafirmando a saúde bucal como direito de todos e dever do Estado.

Na $1^{\text {a }}$ Conferência Nacional de Saúde Bucal -1986, concebe-se a Saúde Bucal, como parte integrante e inseparável da saúde geral do indivíduo, e a relaciona diretamente às condições de alimentação, moradia, trabalho, renda, meio ambiente, transporte, lazer, liberdade, acesso e posse da terra, acesso aos serviços de saúde e à informação de cada indivíduo.

Aluta pela saúde bucal está intimamente vinculada à luta pela melhoria de fatores condicionantes

ISSN 1982-8829 Tempus, actas de saúde colet, Brasília, 13(3), 169-181, set, 2019. Epub Jul/2020 
sociais, políticos e econômicos, o que caracteriza a responsabilidade e dever do Estado em sua manutenção. Destaca também queos segmentos populares organizados deverão participar do planejamento, execução, avaliação, gerenciamento e controle dos Programas de "Saúde Bucal" a nível federal, estadual e municipal, com poder de decisão. (3)

As discussões na $2^{\text {a }}$ Conferência Nacional de Saúde Bucal permitiram a aprovação de diretrizes e estratégias políticas para a Saúde Bucal no país, compreendendo-a como direito de cidadania e construindo um novo modelo de atenção, os recursos humanos, o financiamento e o controle social. Apontava que a efetiva inserção da Saúde Bucal no SUS (Sistema Único de Saúde) deveria desmistificar modelos de programas verticais e de políticas ainda existentes que não levassem em consideração a realidade concreta.

Desta forma, a $2^{\text {a }}$ Conferência Nacional de Saúde Bucal aprovou com muita propriedade que esta inserção se daria através de um processo sob controle da sociedade (Conselhos de Saúde), descentralizado e onde se garanta a universalidade do acesso e a equidade da assistência odontológica, interligados a outras medidas de promoção de saúde de grande impacto social(4).

Por fim a $3^{\text {a }}$ Conferência Nacional de Saúde Bucal 2004 traz a luz que:

As políticas públicas para a construção da cidadania com inclusão social necessitam, seja no plano individual ou coletivo, de ações de diversos setores, implementadas de forma integrada pelas três esferas de governo e pelo conjunto da sociedade. Para tanto, se faz necessária à efetiva elaboração de uma política municipal e estadual de saúde bucal baseada nos princípios e diretrizes do SUS, construída numa base de inclusão e diálogo entre os setores envolvidos, visando à promoção da saúde, educação e reabilitação. Essa política deverá ser legislada pelo poder municipal, como conquista do direito à saúde(5)

Como pode ser visto, a participação da saúde bucal, integrada ao Movimento da Reforma Sanitária, reforça um dos princípios do SUS: a Integralidade das políticas e suas ações.

Delineia, por sua vez, com base nas experiências democráticas das Conferências Nacionais, um conjunto de orientações e proposições, que iriam ser incorporados à Política Nacional de Saúde Bucal, de 2004 e suas diretrizes.

\section{Diretrizes Nacionais para a Política Nacional de Saúde Bucal(PNSB)}

Resultantes de um processo de discussão com gestores da saúde bucal dos estadose orientado pelas deliberações das $1^{\mathrm{a}}$ e $2^{\mathrm{a}}$ Conferências Nacionais de Saúde Bucal, Ministério da Saúde apresenta o documento com as diretrizes para a organização da saúde bucal no âmbito do SUS (6). Constituindo o eixo político básico de proposição para a reorientação das concepções e práticas no campo da saúde bucal, devendo ser entendido como referencial Tempus, actas de saúde colet, Brasília, 13(3), 169-181, set, 2019. Epub Jul/2020 ISSN 1982-8829 
conceitual para a reorientação do modelo de atenção, concebendo-a no espaço da micropolítica. Destacando na construção da Política Nacional de Saúde bucal, o Brasil Sorridente (6).

O principal Programa da Política Nacional de Saúde bucal, o Brasil Sorridente, propõe garantir as ações de promoção, prevenção e recuperação da saúde bucal dos brasileiros, entendendo que esta é fundamental para a saúde geral e qualidade de vida da população e está articulado a outras políticas de saúde e demais políticas públicas, de acordo com os princípios e diretrizes do Sistema Único de Saúde (SUS).(6)

É possível afirmar que a maioria das iniciativas ou articulações envolvendo a PNSB resultou em avanços na inclusão da população brasileira ao seu direito à saúde bucal. Permitiu-se, a partir daí, desenvolver ações e serviços orientados pelo conhecimento da realidade de saúde das mais diversas localidades e para a busca de uma maior resolutividade de suas práticas.

Deve ser destacado que, para além das linhas de Ação do Brasil Sorridente, como Atenção Básica/ESF, fluoretação das águas de abastecimento, implantação dos Centros de Especialidades Odontológicas(CEOS), Laboratórios Regionais de Próteses Dentárias(LRPD), saúde indígena e assistência hospitalar, a Saúde Bucal atuou em interface com outros programas e ações do governo federal, evidenciando sua natureza de política transversal. Podem ser citados: Programa Saúde na Escola, Brasil sem Miséria, Plano Nacional para Pessoas com Deficiência, entre outros.

Há naturalmente, um caminho a percorrer, ajustes e correções de rumo e análise crítica de algumas medidas, mas não tem este estudo o objetivo central de realizar a avaliação detalhada da Política e suas limitações.

Prioriza-se aqui o debate quanto ao horizonte estratégico da manutenção ou não deste direito humano essencial, como direito de cidadania. Neste propósito, revisitar alguns conceitos sobre democracia, direitos e cidadania é imprescindível.

\section{DEMOCRACIA, SOCIEDADE E DIREITOS}

Defender a democracia é defender direitos e evitar retrocessos. Uma luta permanente que envolve a sociedade e qual modelo de Estado se pretende construir. A primeira pergunta é, portanto: para quem é o Estado? Um Estado democrático de direito ou um

Estado que tira de quem não tem para financiar quem não precisa?

Responder a esta indagação, requer tratar a democracia e a cidadania como estruturantes na relação entre sujeitos e direitos. Em um elucidativo artigo, Chauí, orienta:

“O que é um direito? Um direito difere de uma necessidade ou carência e de um interesse. De

ISSN 1982-8829 Tempus, actas de saúde colet, Brasília, 13(3), 169-181, set, 2019. Epub Ju1/2020 
fato, uma necessidade ou carência é algo particular e específico. Alguém pode ter necessidade de água, outro, de comida. Um grupo social pode ter carência de transportes, outro, de hospitais. Há tantas necessidades quanto indivíduos, tantas carências quanto grupos sociais.

Um interesse também é algo particular e específico, dependendo do grupo ou da classe social. Necessidades ou carências, assim como interesses tendem a ser conflitantes porque exprimem as especificidades de diferentes grupos e classes sociais. Um direito, porém, ao contrário de necessidades, carências e interesses não sãoparticulares e específicas, mas geral e universal, seja porque é válido para todos os indivíduos, grupos e classes sociais, seja porque é universalmente reconhecido como válido para um grupo social (como é caso das chamadas - minorias). Ora, isso significa que sob carências, necessidades einteresses encontra-se algo que as explica e determina, isto é, o direito.

Assim, por exemplo, a carência de água e de comida manifesta algo mais profundo: o direito à vida. A carência de moradia ou de transporte também manifesta algo mais profundo: o direito a condições de vida dignas. Da mesma maneira, o interesse, por exemplo, dos estudantes exprime algo mais profundo: o direito à educação e à informação. Em outras palavras, se tomarmos as diferentes carências e os diferentes interesses veremos que sob eles estão pressupostos direitos pelos quais se luta.".(7)

A contribuição de Chauí dialoga com a necessidade objetiva da preservação da democracia e dos direitos como conquistas da sociedade, em processo de conflito e lutas, para que a sociedade alcance sua cidadania. Portanto, o SUS público, universal e democrático, onde nele se insere a saúde bucal como direito, encontra-se contemplado nesta formulação. Ao mesmo tempo, as lutas por esses direitos são insuficientes para a garantia da democracia, necessitando uma permanente articulação com outras lutas, outros movimentos, outras agendas de libertação e de direitos.

O momento político atual no Brasil, representa ameaças à democracia e aos direitos sociais. A clivagem ocorrida no processo de construção da cidadania e inclusão social participativa (de forma mais intensa, a partir do governo Lula em 2003, e interrompida em 2016 com o golpe parlamentar que depôs a presidenta Dilma), busca conduzir o Brasil para um modelo de Estado ultraneoliberal, onde o mercado é a solução de todos os males e o Estado, por sua vez, o grande vilão.

O resultado desta política, se exitosa, levará, às últimas consequências: mais concentração de renda, mais pobreza, extinção de direitos previdenciários(em curso) e trabalhistas(já ocorrido), assim como mais lucros para o sistema financeiro.

A partir de 2019, o governo Bolsonaro, de forma mais intensa, adota a suspensão da soberania nacional, aprofunda a entrega de nossas riquezas nacionais (como o Pré -sal), executa o brutal corte do investimento social público, criminalizando-o através da EC 95 (teto de gastos), onde as 
políticas sociais de saúde educação, entre outras deixam de compor o arco de direitos universais. Enfim, investe na destruição do Estado democrático de direito, adotando medidas com intuito de eliminar as diferentes formas de participação da sociedade, trazendo de volta instrumentos de repressão política contra os legítimos movimentos sociais.

São ameaças e ações que têm sido realizadas e confrontam diretamente os pilares da democracia: a igualdade, a liberdade e a participação nas decisões. Ou seja, seus direitos universais.

\section{BRASIL E A SAÚDE NO PRESENTE E NO FUTURO.}

Diversos estudos de Prospecção Estratégica sobre o SUS foram realizados recentemente, como o que tratou da "Saúde no Brasil em 2030". Na oportunidade foram analisados 03 cenários Prospectivos para o SUS: 1) cenário otimista e possível;2)cenário pessimista e plausível e 3) cenário inercial e provável(8).Considerou-se que em 2030, a população brasileira deverá ser de 216 milhões, com tendência contínua ao envelhecimento. Em relação às questões a considerar, destacam qual o grau de desenvolvimento econômico do Brasil e sua inserção internacional, a sociodemografia nacional, a mobimortalidade da população e a capacidade resolutiva do Estado em resolver as demandas, o financiamento do SUS, entre outros.

Quanto às respostas do SUS e sua estrutura de Oferta, seguem alguns resultados :

No primeiro cenário(otimista e provável), o estudo considera que a Estratégia saúde da Família estará melhor articulada e abrangerá $80 \%$ da população brasileira. Também considera que haverá um aumento do número de leitos hospitalares de tecnologia intensiva, ajustado ao perfil demográfico e que as estruturas para cuidados prolongados e paliativos se expandirão. (8)

No segundo cenário (pessimista e plausível), o estudo aponta impactos de restrição de acesso ao SUS e considera que aumentará muito a oferta de serviços adquiridos de forma privada. Considera também que as iniquidades na distribuição da infraestrutura de serviços em saúde estarão mantidas, com intensificação da fragmentação dos serviços essenciais, comprometendo a universalidade e a integralidade(8).

No terceiro cenário(inercial e provável), o estudo considera que haverá maior capacidade instalada de equipamentos de média e alta complexidade, por meio de seguro privado.. Considera também que haverá um rearranjo da oferta para a organização das redes integradas de saúde, com preenchimento de algumas lacunas na assistência, por meio dos investimentos em ampliação ou readequação da infraestrutura e aquisição de equipamentos, principalmente nas áreas amazônica, nordestina, metropolitanas e de fronteiras, entre outras(8).

Pode-se observar que a atual ofensiva sobre o SUS supera em dificuldades, todos os cenários descritos.Como poderá ser visto, apolítica governamental de austeridade, desmonte do Estado e redução de direitos coloca o SUS sob riscos muito maiores.

ISSN 1982-8829 Tempus, actas de saúde colet, Brasília, 13(3), 169-181, set, 2019. Epub Ju1/2020 
O Centro de Estudos e Debates Estratégicos da Câmara dos Deputados, em publicação de 2017, faz um alerta sobre as perspectivas do SUS, a partir dos dados do IBGE, quando o número de idosos já em 2030 superará o grupo de jovens de até 14 anos (40,65 milhões de idosos para 30,7 milhões de jovens, numa população de 216 milhões de pessoas).

Nesse quadro, tanto a dependência de cuidados por falta de autonomia dos indivíduos idosos quanto o tipo de doenças e agravos que os acometem, colocam as políticas de saúde e de assistência social no centro das preocupações e do planejamento para o futuro. (CEDES, CD, 2017).

Também, ao avaliar"Os impactos do novo regime fiscal para o financiamento do Sistema Único de Saúde e para a efetivação do direito à Saúde no Brasil",um grupo de pesquisadores do IPEA (9) concluiu:"No cenário com taxa de crescimento real do PIB de 2,0\% ao ano, a perda acumulada no período (2016-2036) seria de R \$ 654 bilhões, partindo-se de um limite inicial de 13,2\% da RCL em 2016, e de R\$ 400 bilhões com limite inicial de 15,0\% da RCL”(9).

O estudo aponta maiores dificuldades para os estados mais pobres e também que a pressão da demanda deverá dificultar o corte de despesas aos serviços de urgência e pronto atendimento. Neste caso, com restrição orçamentária, os programas preventivos acabam sendo mais prejudicados. Outro Estudo recente, realizado por pesquisadores da Fiocruz afirma:

"A crise econômica no Brasil combinada com a política de austeridade fiscal pode produzir um contexto mais grave que o vivenciado pelos países desenvolvidos. No país, sobrepõem-se historicamente altos níveis de desigualdade social, subfinanciamento do setor saúde e alta prevalência de doenças crônico-degenerativas com a persistência de doenças infecciosas evitáveis. O quadro mais recente aponta para o retorno de determinantes do aumento da morbimortalidade: para a redução do investimento em proteção social, o aumento da pobreza e a reemergência de doenças transmissíveis por vetores aéreos. Para o Brasil, os efeitos da crise e das políticas de austeridade sobre sistemas cronicamente deficitários é particularmente importante." $\{.$.$\} o cuidado$ dos pacientes portadoras de doenças crônicas não transmissíveis, em que uma porção significativa da população não tem acesso a cuidados de média e alta complexidade, afirmam "Um cenário de crise/austeridade sugere o aumento de números de complicações/sequelas, implicando em uma demanda crescente para procedimentos complexos e aumento da mortalidade prematura, um dos indicadores do monitoramento da agenda 2030(10).

Os limites já impostos ao sistema de saúde universal, em função do subfinanciamento, apontam para a necessidade do Sistema único de Saúde debruçar-se sobre sua atual limitação de serviços de saúde que deem conta da mudança da pirâmide etária brasileira, onde em "um cenário de envelhecimento populacional com elevadas prevalências de doenças crônicas cerca de $77 \%$ da carga total de doença no país e por consequência um aumento da população portadora de 
comorbidades(10).

No caso específico da Saúde bucal, em artigo denominado" O fim do Brasil Sorridente?"(11), Narvaiafirma:A Política Nacional de Saúde Bucal (PNSB), conhecida popularmente como programa "Brasil Sorridente" acabou. Este é apenas mais um dos muitos legados negativos do golpe institucional de 2016, que depôs o governo democrático de Dilma Rousseff. Trata-se do fim do Brasil Sorridente tal como o conhecemos e foi concebido desde o final da ditadura civil-militar, sua estruturação e implementação no governo Lula, bem como os processos avaliativos que o acompanharam desde a institucionalização, em 2003.

"Não há dúvida: o governo Temer decidiu acabar com o Brasil Sorridente. Como símbolo e como política pública. Para compreender essa decisão, que não se anunciou e da qual não se fez alarde, deve-se levar em conta que a imposição da nova PNAB é parte de um processo em cujo início está a chamada "PEC da Morte" (EC 95), que reduz progressivamente por 20 anos os recursos para o SUS. Em seguida veio a decisão sobre a "desregulamentação" dos repasses federais, algo, em princípio, positivo, mas que do modo como foi efetivada, não atendeu ao interesse público na Saúde, conhecida como o "fim dos blocos de financiamento do SUS". Por essa razão, venho afirmando que a decisão sobre a PNAB é uma decisão que expressa uma disputa feroz, muito pesada, por recursos do SUS - que, apesar do estrangulamento financeiro, representa bastante dinheiro. Estou entre os que acreditam que o melhor a fazer com esses recursos que ainda temos, é aloca-los aos serviços públicos, de propriedade do Estado. Mas o ministro Barros, e uma parte da sociedade, quer que esses recursos sejam transferidos para a iniciativa privada, que seria "mais eficiente" em sua alocação e gestão(11).

"Por isto, as decisões de governo a que estou me referindo representam o fim do Brasil Sorridente tal como o conhecemos, que foi uma prioridade de governo, com recursos razoáveis (ou seja, cronicamente subfinanciado como é de amplo conhecimento, mas em equidade com outras "saúdes"). Nesta disputa sobre o destino dos recursos públicos, dentro do SUS e envolvendo a Saúde Complementar, a Saúde Bucal é considerada uma "parte fraca", que deve ceder às pretensões do governo federal"(11).

Esses e outros estudos descrevem, de forma clara, o percurso de ameaças ao SUS e às demais políticas sociais construídas ao longo de décadas no Brasil. A redução do papel do Estado no conjunto de políticas públicas como o SUS, e sua transferência para o setor privado, ou mesmo a extinção dessas políticas, definirá um novo país, mais desigual, menos inclusivo, mais doente.O atual cenário representa um ataque ao pacto que gerou a Constituição Cidadã. Está em curso um processo de desgaste dos direitos adquiridos na Constituição, e, no caso do SUS, uma ofensiva pela sua privatização.

ISSN 1982-8829 Tempus, actas de saúde colet, Brasília, 13(3), 169-181, set, 2019. Epub Jul/2020 


\section{A RESISTÊNCIA DEMOCRÁTICA}

Para buscar impedir este desastre sobre o SUS e sobre todas as políticas sociais conquistadas, é imprescindível que ocorra uma ampla mobilização da sociedade na defesa intransigente do Estado de direito democrático brasileiro, hoje sob forte ataque do grande capital, em especial do capital financeiro internacional.

A defesa do SUS se insere nas lutas gerais por educação, moradia, transporte, emprego e renda, dentre tantas,se insere na mobilização pela Revogação da EC-95 e do decreto 9.759 de 11 de abril de 2019(que extingue colegiados da administração pública federal que tem participação social). Afinal, a "nova" lógica econômica se baseia na redução dos gastos públicos, com o foco nas despesas primárias, onde estão gastos e investimentos sociais em saúde, educação e previdência, custeio da máquina. Não reduz, assim, por exemplo, as despesas financeiras como pagamento da dívida e dos juros da dívida pública com grandes bancos e setor empresarial.

A recuperação da cidadania e o fortalecimento da democracia são, neste sentido, essenciais para impedir que as conquistas sociais alcançadas sejam destruídas.

\section{A SAÚDE BUCAL NAS LUTAS.}

É neste contexto que se coloca a discussão da continuidade e fortalecimento do SUS e da saúde bucal ao alcance de todos.Assim, a luta da saúde bucal como direito de cidadania deve prosseguir permanentemente aliada a iniciativas que façam a defesa da saúde e da democracia como conquistas.De maneira prática e como forma de articular a saúde bucal nesse processo mais amplo, duas questões podem ser mobilizadoras:

A primeira, o fortalecimento da Comissão Intersetorial de Saúde Bucal do Conselho Nacional de Saúde (CISB/CNS), colaborando para que a saúde bucal seja compreendida como integrante das políticas de saúde, pelo conjunto da representação naqueles fóruns (gestores, usuários e trabalhadores de saúde). Além disso, poderia favorecer ocorrência de discussões nos conselhos de saúde estaduais e municipais, da temática de saúde bucal.

Outra importante questão diz respeito à inclusão da saúde bucal na lei 8080/90(lei orgânica da saúde), cujo projeto de lei encontra-se em fase final para deliberação na Câmara dos Deputados, já tendo sido aprovado no Senado.

O entendimento é que este Projeto de lei(PL 8131/2017), apresentado pelo Senador Humberto Costa(PT/PE), traz à luz o direito à saúde bucal para compor as ações do SUS previstas na lei 8080/90(lei orgânica da saúde), dando ao Programa Brasil Sorridente um caráter permanente, compondo umapolítica de Estado, inserida de forma explícita na legislação. Com certeza isto contribuirá com a redução das iniquidades em saúde e na redução dos índices de doenças bucais, além de ser mais um elemento de proteção contra as eventuais políticas de restrição do direito à 
saúde bucal no país.

\section{CONSIDERAÇÕES FINAIS}

A cidadania é um direito a conquistar, através do exercício sistemático da democracia e da mobilização da sociedade. Para tanto é imprescindível criar e incentivar práticas comunitárias que possibilitem o crescimento da consciência sanitária e a mobilização da sociedade civil em torno das questões de saúde. O fortalecimento do SUS é um processo de luta social que deve envolver não só os Conselhos de Saúde, mas toda a sociedade, impactando sempre a melhoria da qualidade de vida de todos os indivíduos através das transformações necessárias do ambiente e da participação digna no processo de trabalho.

A democracia é pressuposto para a cidadania. Ela propicia a ampliação dos direitos e por isto abriga as lutas pelos direitos econômicos, sociais e culturais. (12)

“A cidadania e a democracia são,portanto, construções políticas que devem ser recriadas a cada momento da história de uma sociedade. A expansão da cidadania é parte do processo de democratização do sistema político. A cidadania é considerada um atributo central da democracia, uma vez que a igualdade é ampliada pela expansão do escopo da cidadania e cada vez mais pessoas têm acesso a essa condição (Fleury \& Ouverney (2008)"(12)

Num país em desenvolvimento, como o Brasil, com as enormes desigualdades de renda e oportunidades, a universalidade das políticas sociais, transforma-se em uma exigência para uma efetiva inclusão social. São políticas que devem ser patrocinadas pelo Estado como um sujeito de direitos coletivos, de uma sociedade democrática.

Nesse sentido, alterações políticas como a revogação da emenda constitucional ${ }^{\circ}$ 95, o retorno dos investimentos em saúde, educação, ciência e tecnologia, e a retomada de seus principais programas e políticas sociais, são essenciais.

A defesa do SUS é a defesa da democracia e da cidadania. Neste sentido a implementação das resoluções da $16^{\text {a }}$ Conferência Nacional de Saúde e o fortalecimento dos espaços do Controle social do SUS são fundamentais. A isto se juntam as lutas por direitos, liberdade e igualdade, contra as privatizações e o desmonte do Estado de bem-estar social que se colocava em perspectiva.

Há em curso, tentativas de "substituição" do SUS, por modelos de cobertura restrita e de financiamento privado. A política de austeridade em curso sustenta estas alternativas, com apoio e contribuições de instituições internacionais.

No Relatório consolidado da $16^{\mathrm{a}} \mathrm{CNS}$, é possível destacar a riqueza e dimensão do SUS, pelo qual se deve continuar lutando, ou seja, um SUS para todos. "O compromisso de fortalecimento da Estratégia de Saúde da Família como ordenadora do cuidado, visando cobertura de 100\% do ISSN 1982-8829 Tempus, actas de saúde colet, Brasília, 13(3), 169-181, set, 2019. Epub Ju1/2020 
território, possibilitando a equiparação de equipes de saúde da família e saúde bucal, bem como uma equipe NASF para o máximo quatro equipes de saúde da família, garantindo assim equidade para as populações em situação de vulnerabilidade: negra, em situação de rua, LGBT, do campo, das águas e florestas, cigana, profissionais do sexo, com doenças raras, ribeirinha, de imigrantes, circenses, de refugiados, moradores e moradores de ocupações, refugiadas, em situação prisional, indígenas e quilombolas." Na prática, a $16^{\mathrm{a}} \mathrm{CNS}$ reafirma os princípios de universalidade, integralidade e equidade do SUS.

A luta pelo direito à saúde bucal, pelo SUS e por políticas sociais que garantam bem-estar e qualidade de vida para todos, faz parte deste arco de direitos de cidadania, opondo-se aos interesses e privilégios do grande capital e seus aliados. A luta pela sobrevivência do SUS, assim, está vinculada diretamente à democracia e à cidadania. Nesta direção, em relação à saúde bucal do povo brasileiro, num horizonte estratégico para os próximos anos, observa-se que a mais importante conquista, refere-se a tornar irreversível a saúde bucal como direito humano essencial e direito de cidadania, inserindo-a no rol das políticas do SUS.

\section{REFERÊNCIAS}

1. Barbosa S do N. Responsabilidade Social e Saúde - estudo de caso sobre a Pol í tica Nacional de Sa ú de Bucal no Brasil . FACULDADE DE CIÊNCIAS DA SAÚDE PROGRAMA DE PÓS-GRADUAÇÃO EM CIÊNCIAS DA SAÚDE. 2015.

2. Fiocruz. Saúde é democracia. PenseSUS.

3. Brasil. Ministério da Saúde. $1^{\text {a }}$ Conferência Nacional de Saúde Bucal - relatório final. $1986 ; 1-11$.

4. Saúde. BM da. Brasil. Ministério da Saúde. 2004. 1-148 p.

5. Saúde. BM da. 2a Conferência Nacional de Saúde Bucal - relatório final. 1993;

6. Brasil. Ministério da Saúde. Diretrizes da Política Nacional de Saúde Bucal. Portal da Saúde. 2004;16.

7. Chaui M. Democracia e sociedade autoritária. Comun Informação. 2013;15(2):149-61.

8. Fiocruz. A saúde no Brasil em 2030: estrutura do financiamento e do gasto setorial - Vol. 4. A saúde no Brasil em 2030: estrutura do financiamento e do gasto setorial - Vol. 4. 2013.

9. Vieira, F; Benevides RP. Os impactos do novo regime fiscal para o financiamento do sistema Único de Saúde e para a efetivação do direito à saúde no Brasil. IPEA. 2016;

10. Mendes. joyce M de ASRP-SLVP. Políticas de Austeridade e Seus Impactos na Saúde: 
$181 / /$

um debate em tempos de crise. Cent Estud Estratégicos da Fiocruz. 2018;1:40.

11. Narvai PC. O fim do Brasil Sorridente? CEBES. 2017.

12. Fleury S. POLITICA DE SAUDE POLITICA SOCIAL. In: Giovanella L et al., editor. Políticas e sistema de saúde no Brasil. 1ª. Editora FIOCRUZ; 2008. p. 1-42.

Artigo apresentado em outubro de 2019 Artigo aprovado em janeiro de 2020 Artigo publicado em julho de 2020 